\title{
Ontogenetic diel vertical migration behaviors of the marine planktonic copepods Calanus pacificus and Metridia lucens
}

\author{
Kenric E. Osgood, Bruce W. Frost \\ School of Oceanography, WB-10, University of Washington, Seattle, Washington 98195, USA
}

\begin{abstract}
Daytime and nighttime vertically stratified zooplankton samples spanning the entire water column were obtained from Dabob Bay, Washington, USA, during several years. Vertical distributions of all the copepodid stages of Calanus pacificus and Metridia lucens were analyzed from 8 cruises representing the range of seasons, as well as several dates when inferred invertebrate or vertebrate predation pressures on zooplankton were strong or weak. Migration behaviors of similar-sized stages of $C$. pacificus and $M$. lucens differed. $C$. pacificus was closely associated with the surface waters; a large percentage of every stage was always in the surface $50 \mathrm{~m}$ at night except when the C5s were in diapause. During the day the different stages of $C$. pacificus showed varying degrees of avoidance of the surface layers, with the older, larger stages generally being deeper. The $C 4$ and younger stages were particularly tied to the surface waters, with the majority of the population usually in the top $25 \mathrm{~m}$ during the day and night. $M$. lucens was less strongly associated with the surface layers. While the adult females, and usually the C5s, underwent a normal diel vetical migration (DVM), entering the surface $50 \mathrm{~m}$ at night, the vast majority of the adult males always stayed below $75 \mathrm{~m}$. The $\mathrm{C} 4$ and younger stages showed more varied behavior. On some dates they underwent a reverse DVM, avoiding the surface $25 \mathrm{~m}$ at night, at other times they avoided the surface $10 \mathrm{~m}$ particularly during the day, while on still other dates the $\mathrm{C} 3$ and younger stages avoided the surface $25 \mathrm{~m}$ day and night. On most dates there were significant portions of all the stages in the deepest layers sampled. Differences in the 2 species' migration behavior may be due to differences in their susceptibility to predation, or some additional aspect of their biologies.
\end{abstract}

KEY WORDS: Diel vertical migration $\cdot$ Calanus pacificus $\cdot$ Metrida lucens $\cdot$ Zooplankton - Dabob Bay

\section{INTRODUCTION}

Calanus pacificus Brodsky and Metridia lucens Boeck co-occur and often numerically dominate the mesozooplankton in the shelf and slope waters of the eastern temperate Pacific Ocean (Star \& Mullin 1981, Gardner \& Szabo 1982) and across much of the oceanic subarctic Pacific (Park 1968, Minoda 1971, Marlowe \& Miller 1975). Despite their importance in the same areas, and their superficial morphological similarities (including body size), few studies have compared aspects of the ecologies of these 2 species (see Bollens et al. in press). The comparative studies conducted to date have focused primarily on the adult females.

Diel vertical migration (DVM) behavior is a significant aspect of the ecology of the adults of both copepod species (Bollens et al. in press). Given that body size of prey is an important factor in prey selection by both vertebrate and invertebrate predators (e.g. Brooks 1968, Landry 1978, Sullivan 1980, Koslow 1981, Yen 1985), different developmental stages of copepods are potentially exposed to different predation pressures during their growth. Since some developmental stages of Calanus pacificus and Metridia lucens are similar in size, they may be exposed to similar predation pressures. With predation being invoked as the primary selective force behind DVM (see Lampert 1989, Frost \& Bollens 1992), different developmental stages may be expected to exhibit different DVM behavior if predation is a major factor in their population growth. In fact, Neill (1992) observed this for a species of freshwater calanoid copepod. Thus, ignoring other aspects 
of their behaviors, stages of $C$. pacificus and $M$. lucens which are of the same size may be expected to exhibit similar DVM behaviors.

This paper presents daytime and nighttime vertical distribution data from one location for the copepodid stages of Calanus pacificus and Metridia lucens in different seasons. The vertical distribution patterns are interpreted in relation to various predation regimes possibly experienced by particular stages of the 2 species. Seasonal and life history effects are also discussed.

\section{METHODS}

Zooplankton samples were obtained from the deep (193 m), central basin of Dabob Bay, Washington, USA $\left(47^{\circ} 45^{\prime} \mathrm{N}, 122^{\circ} 50^{\prime} \mathrm{W}\right)$ from a ship tied to an anchored buoy. Dabob Bay is a fjord within which the circulation is limited such that the same populations of zooplankton can be sampled over the course of at least several days (see Frost 1988). Samples used in this study were collected during 8 cruises between 1973 and 1986 (Table 1). For the 1973, 1981, and 1982 samples, successive vertical hauls with a single $1 \mathrm{~m}$ diameter (except September 1982 when a $60 \mathrm{~cm}$ diameter net was used), $216 \mu \mathrm{m}$ mesh, Puget Sound closing net (Miller et al. 1984) were made to obtain samples from discrete depth strata. A $216 \mu \mathrm{m}$ mesh retains all of the copepodid stages of Calanus pacificus and all but the $\mathrm{C} 1 \mathrm{~s}$ of Metridia lucens. Based on comparisons of catches with $73 \mu \mathrm{m}$ mesh nets, most $\mathrm{C} 1 \mathrm{M}$. lucens are also caught with a $216 \mu \mathrm{m}$ mesh. In 1973, samples were obtained from $175-150,150-125,125-100,100-75,75-50$, 50-25, and 25-0 m. In 1981 and 1982, sam-
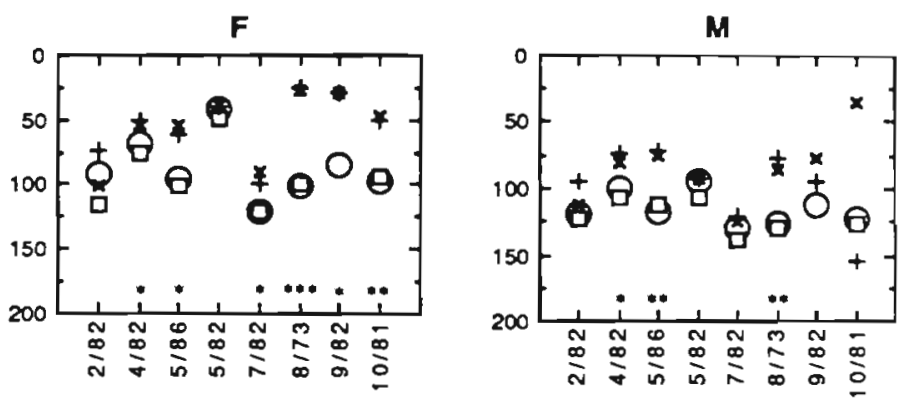

C 5
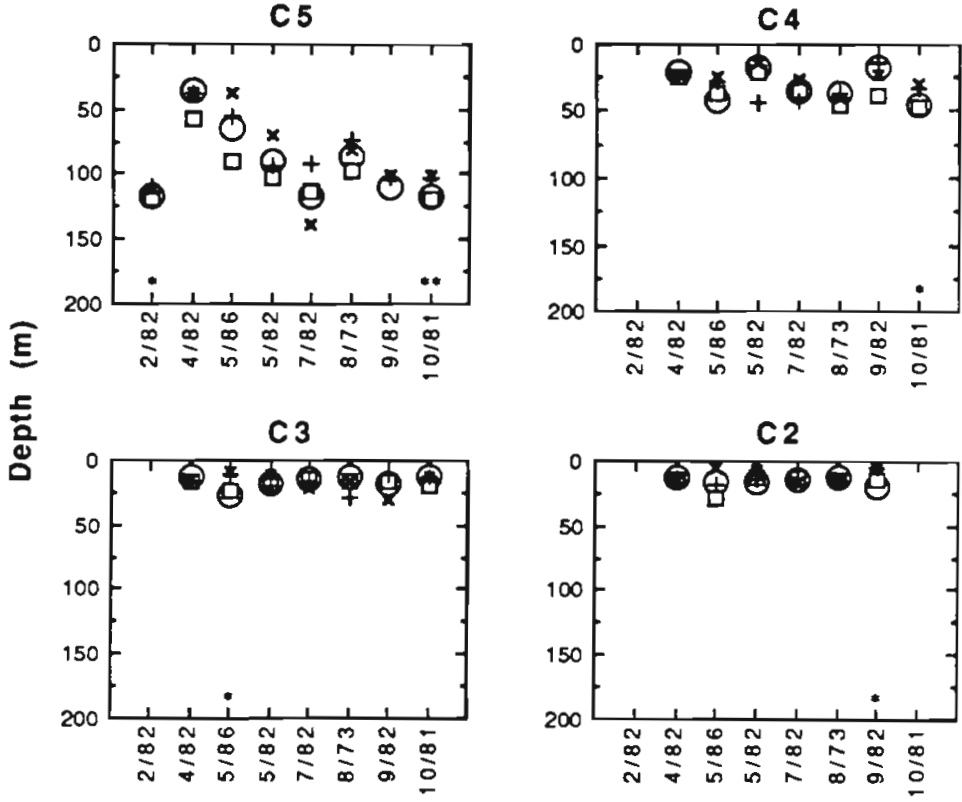

C 2

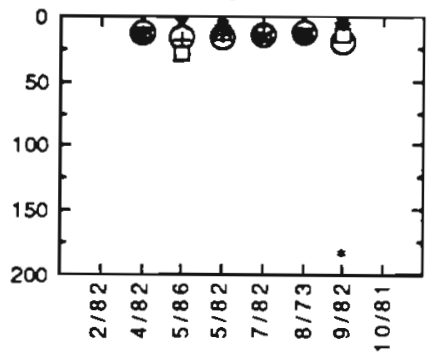

C 1

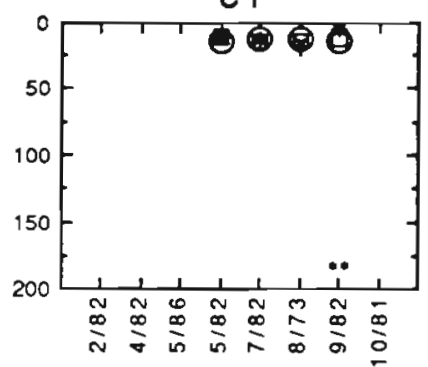

Fig. 1. Calanus pacificus Weighted mean depths of the copepodid stages for each vertical series of samples counted in the study. $(0, \square)$ Replicate day series; $(+, x)$ Replicate night series. Statistically significant differences between the day and night WMDs are indicated. Probability that mean day and night WMDs different by chance: 'p $<$ $0.05 ; \cdots p<0.01 ; \cdots p<0.001$
Table 1. Sampling dates and the times around which each collection of vertical series of samples were centered. It generally took 45 min to complete each series. Sampling times when it was dark are underlined

\begin{tabular}{|c|c|c|c|c|c|}
\hline \multicolumn{2}{|c|}{ Dates } & \multicolumn{4}{|c|}{ Sampling times (h) } \\
\hline 3-4 Aug & 1973 & $23: 55$ & $01: 08$ & $11: 33$ & $13: 00$ \\
\hline $23-24$ Oct & 1981 & 22.50 & $23: 00$ & $10: 30$ & $10: 40$ \\
\hline $19 \mathrm{Feb}$ & 1982 & $01: 00$ & $11: 30$ & $17: 32$ & $19: 35$ \\
\hline $29-30 \mathrm{Apr}$ & 1982 & $17: 59$ & $00: 22$ & $01: 14$ & $10: 35$ \\
\hline 27-28 May & 1982 & $17: 35$ & $00: 25$ & $01: 20$ & $12: 20$ \\
\hline $9-10 \mathrm{Jul}$ & 1982 & $18: 55$ & $\underline{01: 22}$ & $\underline{02: 20}$ & $12: 10$ \\
\hline $16-17 \mathrm{Sep}$ & 1982 & $18: 05$ & $\overline{00.08}$ & $\overline{00: 52}$ & $09: 04$ \\
\hline 6-7 May & 1986 & $23: 25$ & 01.07 & $\overline{10: 35}$ & $12: 35$ \\
\hline
\end{tabular}

ples were obtained from 185-125, 125-75, 75-50, $50-25,25-0$, and usually $10-0 \mathrm{~m}$. In 1986, a vertically hauled, multiple sample, closing net $11.0 \mathrm{~m}^{2}, 333 \mu \mathrm{m}$ mesh) was used to sample discrete depth strata in a single vertical haul. Samples were obtained from $175-125,125-75,75-50,50-25,25-10$, and $10-0 \mathrm{~m}$. A $333 \mu \mathrm{m}$ mesh net retains all copepodid stages except $\mathrm{C} 1$ of $C$. pacificus and $\mathrm{C} 1$ and $\mathrm{C} 2$ of $M$. lucens. In comparisons of catches between the different nets used, no differential gear avoidance or selection was found due to the different net mouth areas.

On all cruises, 2 daytime and 2 nighttime vertical series of samples were collected and immediately pre- 
served in 10\% formalin-seawater solution, buffered with sodium borate. Abundances of the copepodid stages of Calanus pacificus and Metridia lucens in the preserved samples were determined from replicate subsamples taken with a stempel pipette. For each developmental stage of both species the weighted mean depth was calculated for each vertical series of samples as WMD = $\left(\sum \mathrm{n}_{i} \Delta_{l} d_{l}\right) / \sum \mathrm{n}_{l} \Delta_{l}$, where $\mathrm{n}_{i}$ is the abundance ind. $\mathrm{m}^{-3}$ ) in the depth interval $\Delta_{i}$ whose midpoint is $d_{i}$. The presence of DVMs was determined by testing for equality of the mean day and night WMDs with a 2-sample t-test. This test assumes the day and night WMDs are each distributed normally. In addition, migration magnitudes may have been underestimated, as the samples were not necessarily obtained when the copepod populations were at their minimum or maximum depth distributions. Therefore, day and night mean WMDs should be regarded as approximations.

A vertical profile of the water temperature to at least $50 \mathrm{~m}$ was obtained with a CTD or bathythermograph on each cruise. In addition, the vertical distribution of chlorophyll a was obtained for most dates from samples collected at 5 to 7 depths in the upper $30 \mathrm{~m}$ (see Frost 1988).

\section{RESULTS}

\section{Interspecific comparisons}

The data set is summarized 2 ways. Weighted mean depths of all copepodid stages of Calanus pacificus and Metridia lucens for each vertical series of samples are presented in Figs. 1 \& 2. DVM behavior was inferred when daytime WMD was statistically significantly different from nighttime WMD. The full range of behaviors of all stages is illustrated with mean day and night vertical distributions for selected dates shown in Figs. 3 to 12. The adults, i.e. C6s, are differentiated by sex. Both species exhibited ontogenetic changes in vertical distribution and migration behavior, but, for any given copepodid stage, each species could also have different migration behavior on different dates. The exceptions to this were the $\mathrm{C} 1$ $C$. pacificus and the adult male $M$. lucens. $C$. pacificus C1s were always concentrated in the uppermost depth strata sampled day and night, while the vast majority of the adult male $M$. Iucens remained below $75 \mathrm{~m}$ day
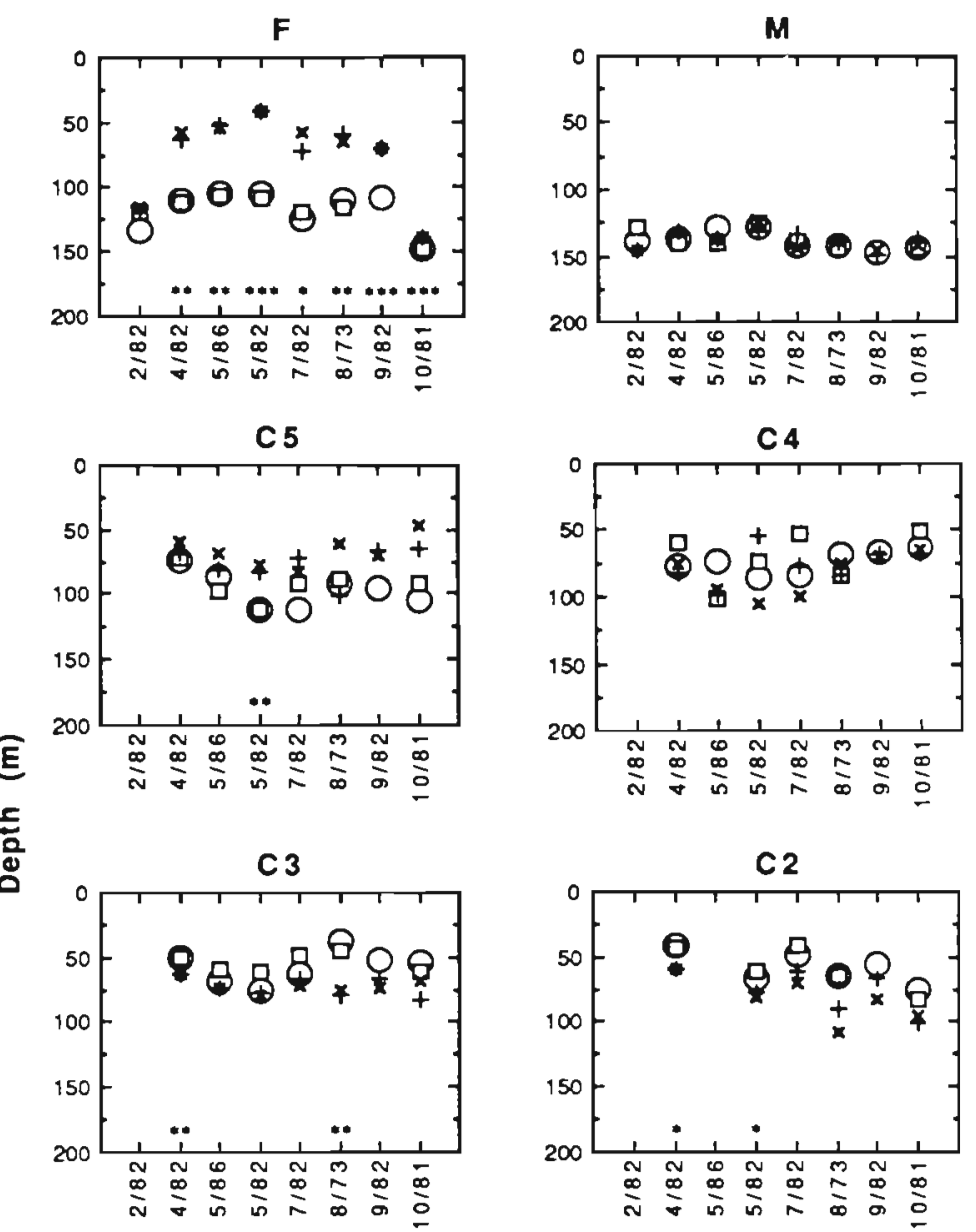

C 1

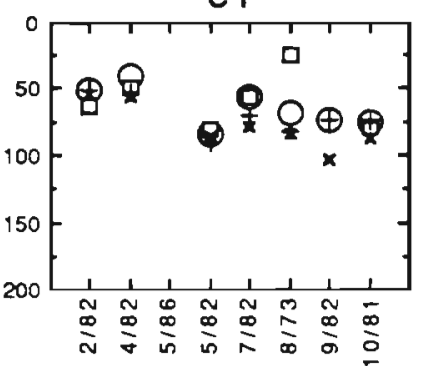

Fig. 2. Metridia lucens. Weighted mean depths of the copepodid stages for each vertical series of samples counted in the study. Symbols as in Fig. 1

and night on all dates, with only a very small percentage of them occurring above $75 \mathrm{~m}$ at night. Even though some of the copepodid stages of $M$. lucens and $C$. pacificus overlap in body size (Table 2), there were very few resemblances between species in the behavior of similar-sized individuals. The majority of the young copepodid stages ( $\mathrm{C} 1$ to $\mathrm{C} 4$ ) of $\mathrm{C}$. pacificus stayed in the upper $25 \mathrm{~m}$ at all times, whereas those of $M$. lucens were distributed throughout the water column (e.g. see Figs. 5 \& 10). In addition, adult male C. pacificus ranged throughout the water column and at times exhibited significant DVM behavior (e.g. see Fig. 6), while the $M$. lucens males stayed below $75 \mathrm{~m}$ 

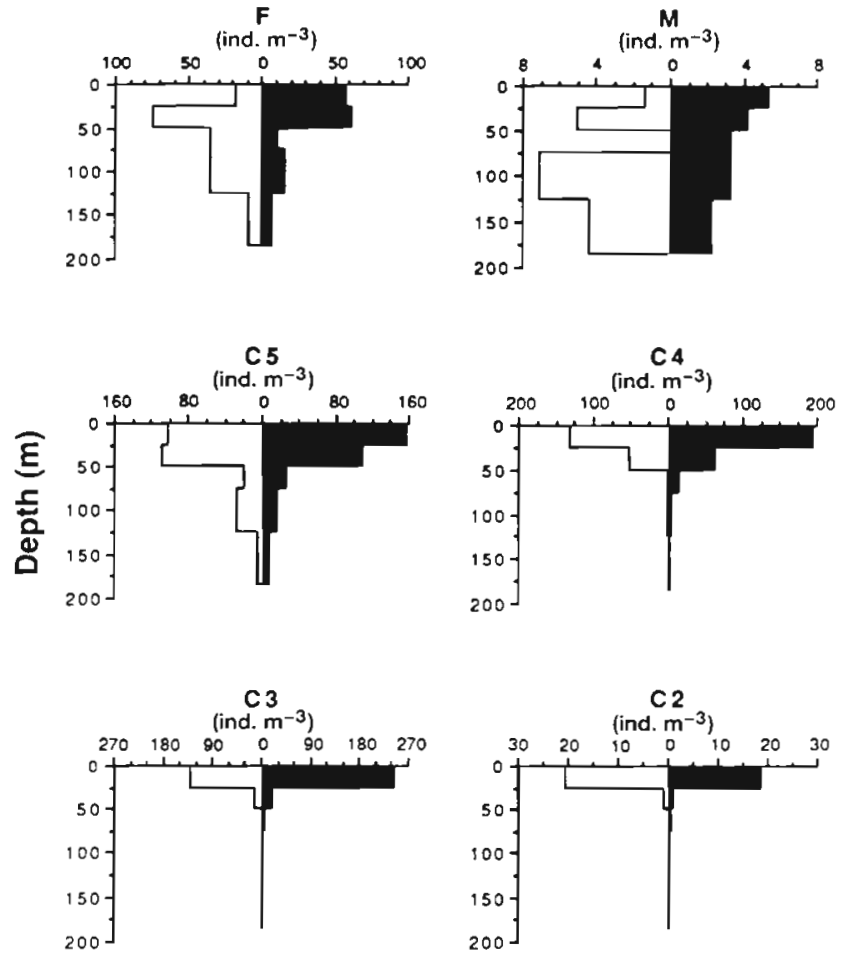

29-30 April 1982

Fig. 3. Calanus pacificus. Vertical distributions of the copepodid stages in Dabob Bay during April 1982. Each day (open) and night (shaded) vertical distribution is the mean of 2 vertical series of samples

day and night (e.g. see Fig. 8), as already mentioned. Finally, although females of both species generally exhibited normal DVM behavior, the vertical distribution patterns of $M$. lucens females were more regular, with few females ever in the surface $50 \mathrm{~m}$ during the day, whereas at times, the majority of the C. pacificus females were there.

\section{Calanus pacificus vertical distributions}

Calanus pacificus adult females usually underwent a normal DVM (Figs. 3 to 7 ) and the WMD plots show statistically significant differences in the day and night mean depths for $C$. pacificus females on all but 2 dates (Fig. 1). One of these dates, February 1982, was a time when adult $C$. pacificus had just started to appear from the overwintering stage in deep water, and the few adults tended to stay in deep water. The other date, late May 1982, was a time when the majority of the females remained in the top $50 \mathrm{~m}$ of the water column day and night (Fig. 5).

Calanus pacificus adult males demonstrated a general avoidance of the surface layers during daylight
Table 2. Calanus pacificus, Metridia lucens. Median prosome lengths (mm) of 10 or more individuals on 30 April 1982

\begin{tabular}{|ccc|}
\hline Stage & C. pacificus & M. lucens \\
\hline F & 2.45 & 1.80 \\
M & 2.20 & 1.24 \\
C5 & 2.03 & 1.29 \\
C 3 & 1.60 & 0.96 \\
C2 & 1.20 & 0.76 \\
C1 & 0.90 & 0.55 \\
\hline
\end{tabular}

and a tendency for a broader vertical distribution during the night. This resulted in the male population as a whole displaying normal DVM behavior on most dates and significantly so on 3 dates (Fig. 1).

C5 Calanus pacificus were even less regular in their migration behavior. They showed weak normal DVM behavior on most dates, but statistically significant DVM was observed on only 2 dates, February 1982 and October 1981. At both times most of the overwintering C5s stayed below $75 \mathrm{~m}$ day and night, but a few migrated to the surface layers at night (data not shown). The one time when no C5s were present in the
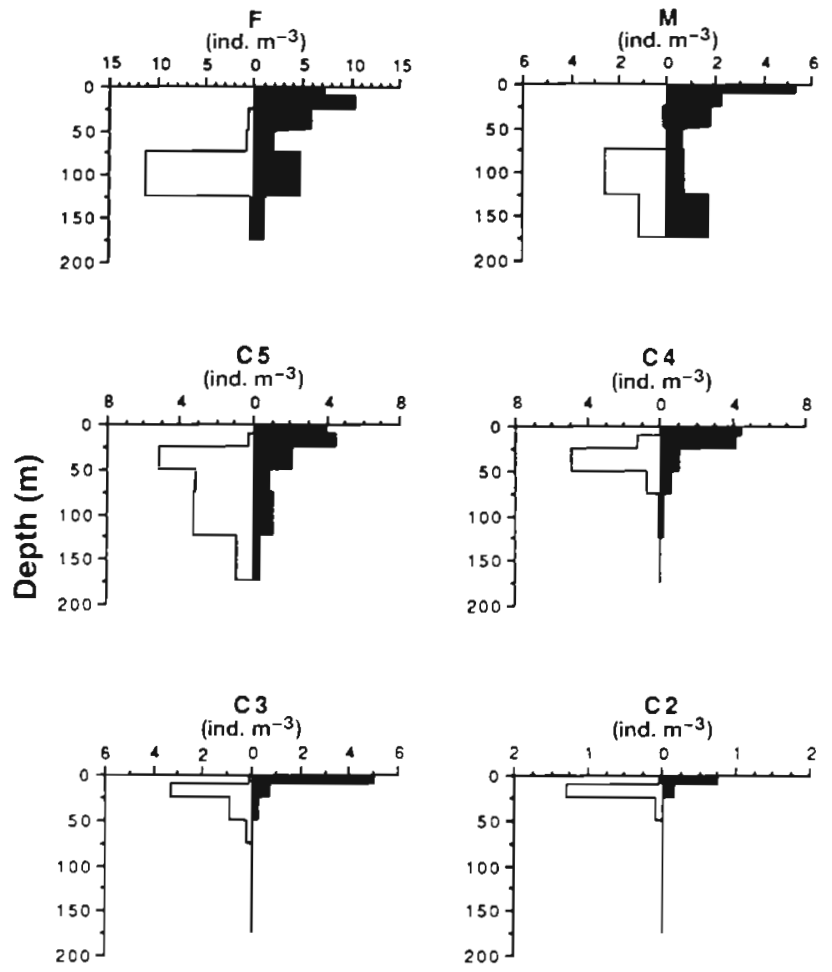

6-7 May 1986

Fig. 4. Calanus pacificus. Vertical distribution. As in Fig. 3 except for May 1986 

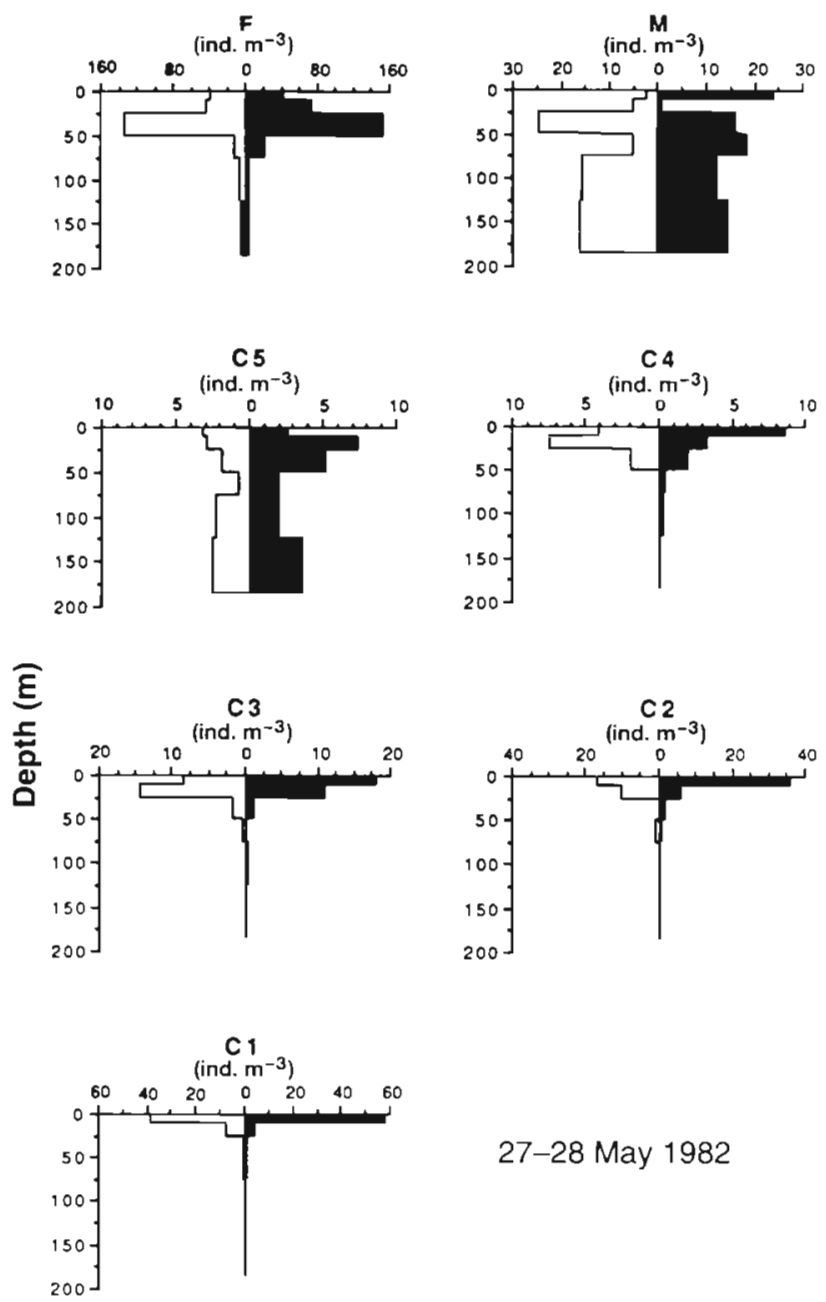

\section{7-28 May 1982}

Fig. 5. Calanus pacificus. Vertical distribution. As in Fig. 3 except for May 1982

10-0 m layer (and very few in the 25-10 m layer) during the daytime was May 1986. However, because of variability in the data for the deeper layers, the apparent DVM of $\mathrm{C} 5 \mathrm{~s}$ on this date was not supported by comparisons of day and night WMDs.

C4 Calanus pacificus were either nonmigratory, being concentrated in the top 25 or $50 \mathrm{~m}$ day and night, or underwent a normal DVM over a narrow depth range. A very fine-scale migration is evident in the May 1982 vertical distributions (Fig. 5), where the peak abundances were in the $25-10 \mathrm{~m}$ layer and the 10-0 $\mathrm{m}$ layer during the day and night respectively. A slightly deeper migration was evident in May 1986 when peak abundances shifted from 50-25 m during the day to the 25-10 and 10-0 m layers during the night (Fig. 4). Also on this date, almost no C4s were in the 10-0 m layer during the day while on all other dates where a 10-0 m sample was counted, significant portions of the population were in this layer. These vertical migrations were not statistically significant based on differences in daytime and nighttime WMDs (Fig. 1). When an apparent migration is over a very short depth range, as at this time, the statistical comparison of daytime and nighttime mean depths is especially sensitive to variability between the 2 vertical series. In such circumstances, an apparent vertical migration may not be supported by statistically significant differences between day and night WMDs.

Vertical distributions of Calanus pacificus C3s were very similar to, though somewhat shallower than, those of the $\mathrm{C} 4 \mathrm{~s}$. On dates where no 10-0 $\mathrm{m}$ samples were counted, the maximum abundances of the C3s was in the 25-0 $\mathrm{m}$ layer day and night with no vertical movement evident (e.g. Figs. 3 \& 6). During May and September 1982, there was evidence that the maximum concentrations of C3s shifted from the 25-10 m layer during the day to the $10-0 \mathrm{~m}$ at night (Figs. $5 \& 7$ ). However, on both dates there was a significant portion
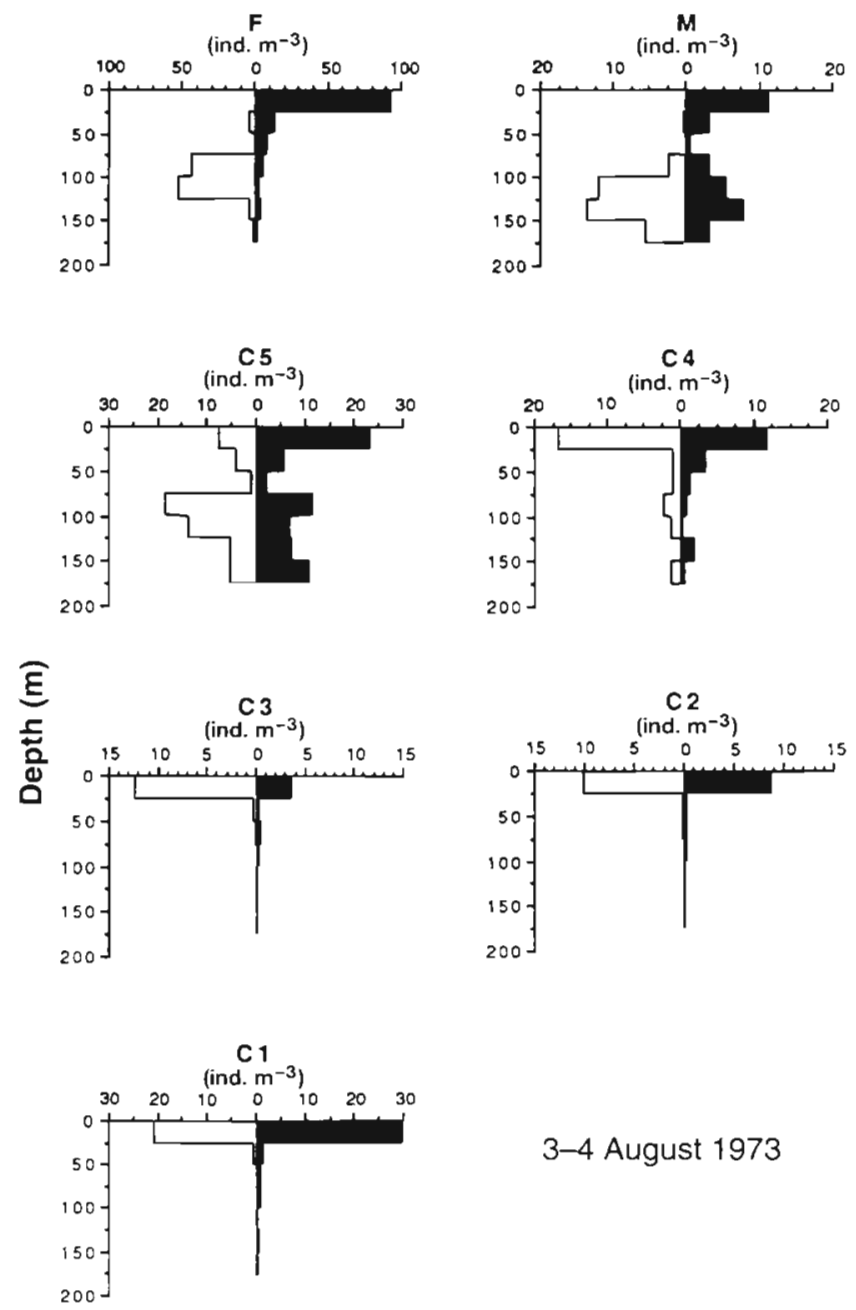

3-4 August 1973

Fig. 6. Calanus pacificus. Vertical distribution. As in Fig. 3 except for August 1973 

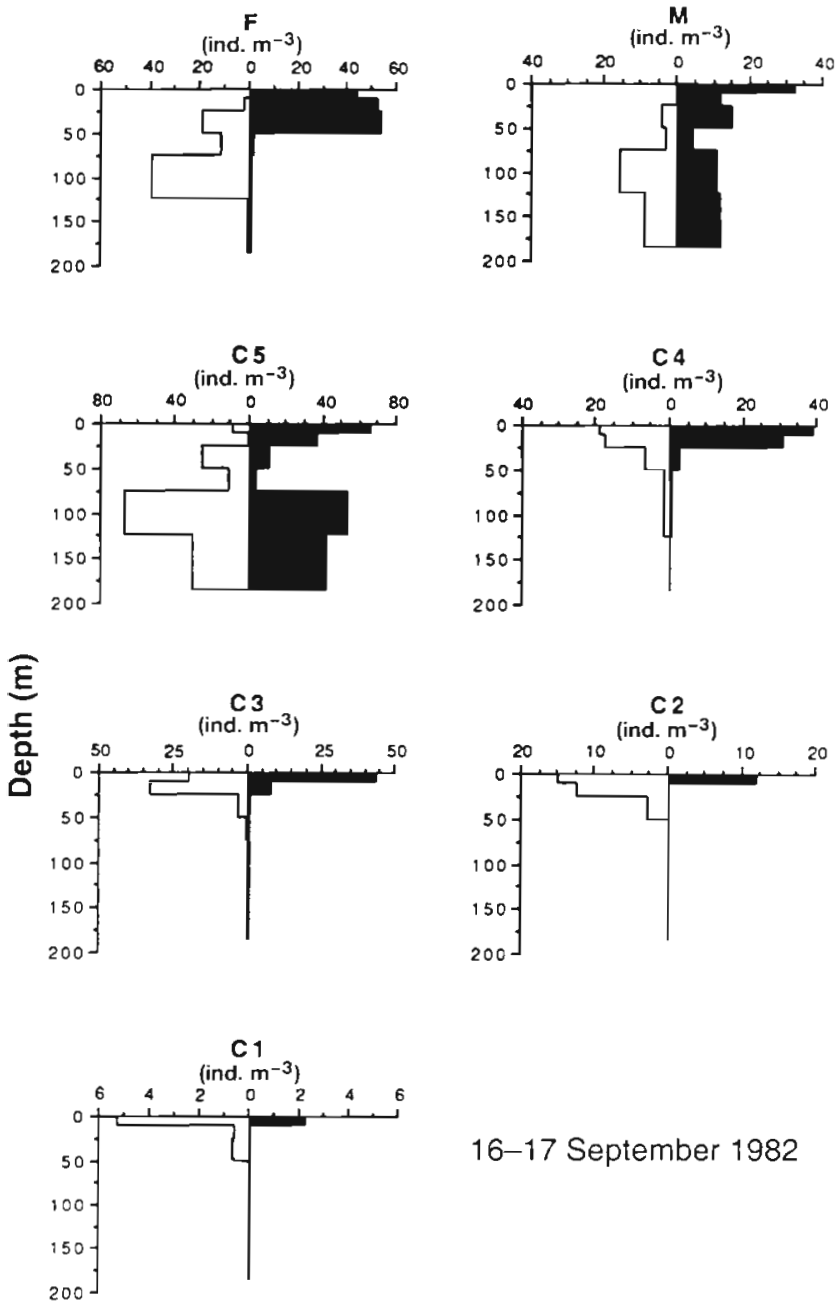

16-17 September 1982

Fig. 7. Calanus pacificus. Vertical distribution. As in Fig. 3 except for September 1982

of the population in the top $10 \mathrm{~m}$ during the day. Only in May 1986 were there very few C3s in the 10-0 m layer during the day (Fig. 4).

C2 Calanus pacificus continue the trend of younger copepodid stages being distributed slightly more shallowly than the next older stage. The highest concentrations of $\mathrm{C} 2 \mathrm{~s}$ were always in the $10-0 \mathrm{~m}$ or $25-0 \mathrm{~m}$ layer day and night, except during May 1986 when very few were in the $10-0 \mathrm{~m}$ layer during the day (Fig. 4). On all dates when a 10-0 m layer was counted, the majority of the $\mathrm{C} 2 \mathrm{~s}$ in the layers below $10 \mathrm{~m}$ migrated up into the top $10 \mathrm{~m}$ at night (Figs. 4,5 \& 7).

C1 Calanus pacificus showed little indication of any migration on the scales sampled (Figs. 5 to 7 ). There was a statistically significant difference between the day and night WMDs calculated for September 1982 (Fig. 1). However, the abundances, and therefore the counts, of the C1s on this date were very low below
$10 \mathrm{~m}$, so this difference may not, in fact, be real. Based on the other copepodids, May 1986 was a date when a migration by the C1s might have been expected, but the $\mathrm{C} 1 \mathrm{~s}$ were not sampled on this date due to the coarse mesh size of the nets used.

\section{Metridia lucens vertical distributions}

The majority of the adult female Metridia lucens undertook pronounced DVMs on all but 2 of the sample dates (Fig. 2). In February 1982, and October 1981 only a small fraction of the population migrated into the surface $50 \mathrm{~m}$ at night (data not shown). Even in October, though, there were enough females migrating to make the day and night WMDs significantly different.

As previously stated, the adult male Metridia lucens displayed virtually identical day and night vertical dis-
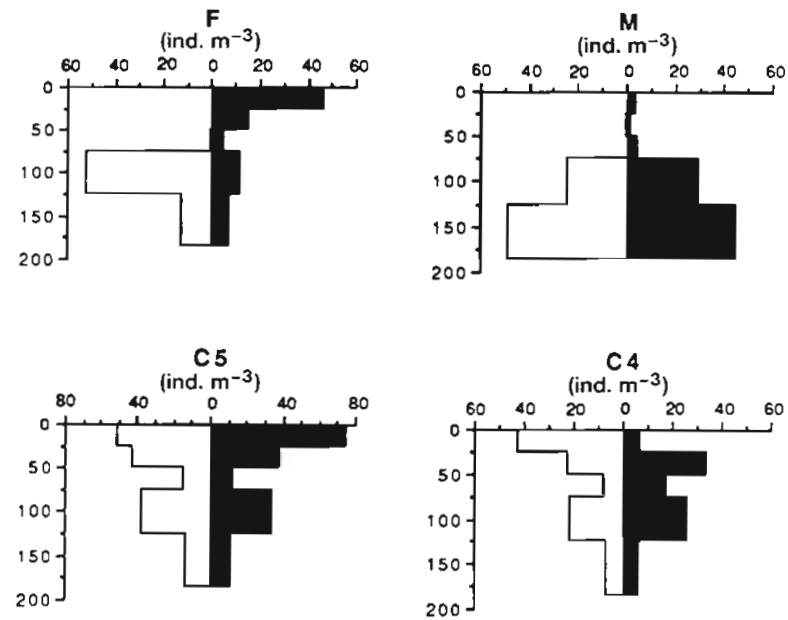

$\widehat{\underline{E}}$
营
ڤั
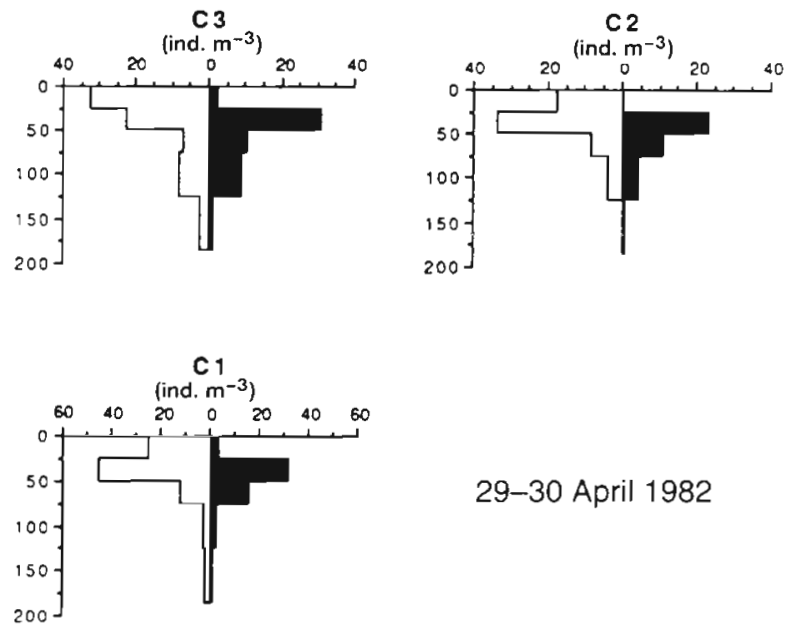

29-30 April 1982

Fig. 8. Metridia lucens. Vertical distributions of the copepodite stages during April 1982. Bars as in Fig. 3 

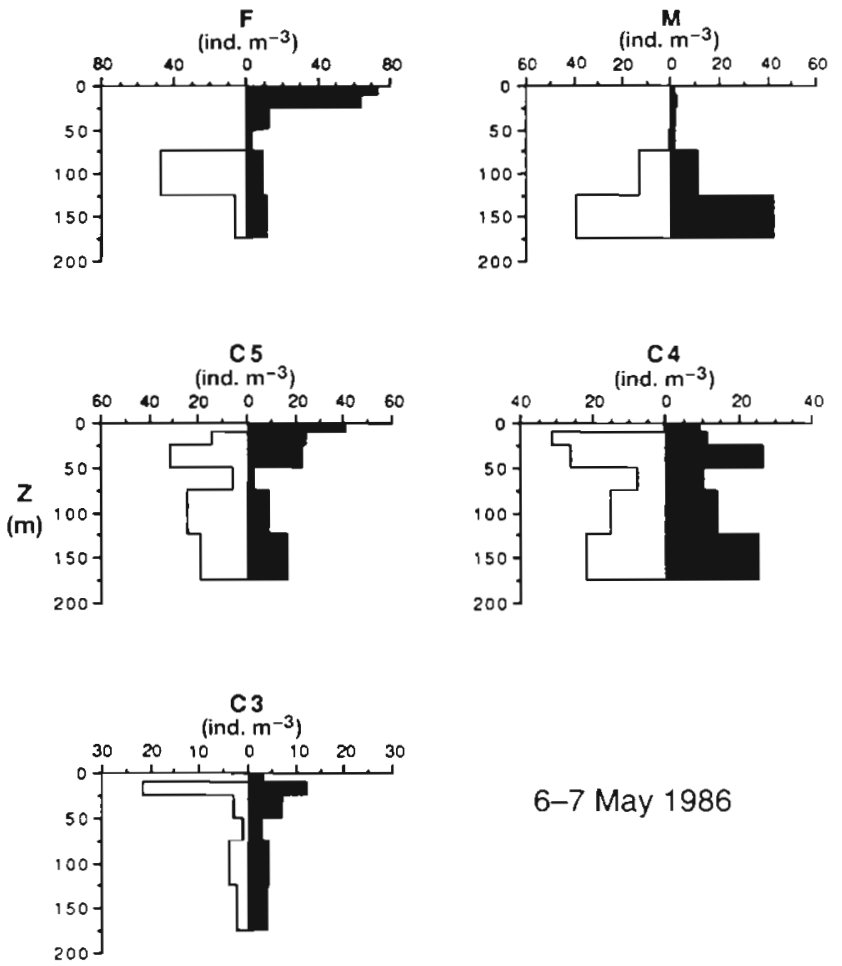

\section{6-7 May 1986}

Fig. 9. Metridia lucens. Vertical distributions. As in Fig. 8 except for May 1986

tributions on all cruises. The vast majority remained below $75 \mathrm{~m}$ day and night, with only a small percentage migrating above $75 \mathrm{~m}$ at night (e.g. Fig. 8).

The vertical distributions of the C5 Metridia lucens were much more variable than those of the adults. They often were bimodally distributed by depth during both day and night (Figs. $8 \& 9$ ). On some dates, a portion of the C5s underwent a normal DVM (Figs. 10 to 12). Even in May 1986, when C5s were bimodally distributed day and night, they avoided the surface $10 \mathrm{~m}$ during the day (Fig. 9). To determine whether bimodal vertical distributions, and migratory versus nonmigratory behavior, were related to sex, the abundances of C5 males and C5 females were estimated in the 0-25 and 75-125 or 125-185 m layers at night on several dates. No differences in the proportions of male and female C5s were found between the 2 layers on any date.

C4 Metridia lucens tended to be broadly distributed throughout the water column, with apparent preference or avoidance of particular layers at certain times. Specifically, in April 1982 maximum concentrations of C4s were present in the 25-0 m layer during the day but they tended to avoid this layer at night (Fig. 8). A similar pattern also occurred in August 1973 (Fig. 11). In May 1986, they avoided the top $10 \mathrm{~m}$ during the day, while during September 1982, the C4s became particularly concentrated in the surface $10 \mathrm{~m}$ at night (Fig. 12).

Metridia lucens C3s showed varied behavior. In April 1982 and August 1973 they displayed statistically significant reverse DVM behavior (Figs. 2, 8 \& 11). On these dates, there was a particular tendency to be concentrated in the top $25 \mathrm{~m}$ during the day but to avoid this layer at night. During May 1986 and May and September 1982 , the $\mathrm{C} 3 \mathrm{~s}$ were rare or absent in the top 10 or $25 \mathrm{~m}$ during the day, yet at night their avoidance of this layer was less strict (Figs. 9, 10 \& 12). In fact, in September, the C3s actually concentrated in the top $10 \mathrm{~m}$ at night.

The C2 Metridia lucens avoided some portion of the surface $25 \mathrm{~m}$ on all dates sampled. In April 1982 and August 1973, they totally avoided the 25-0 m layer at night, while during the day a substantial fraction of the
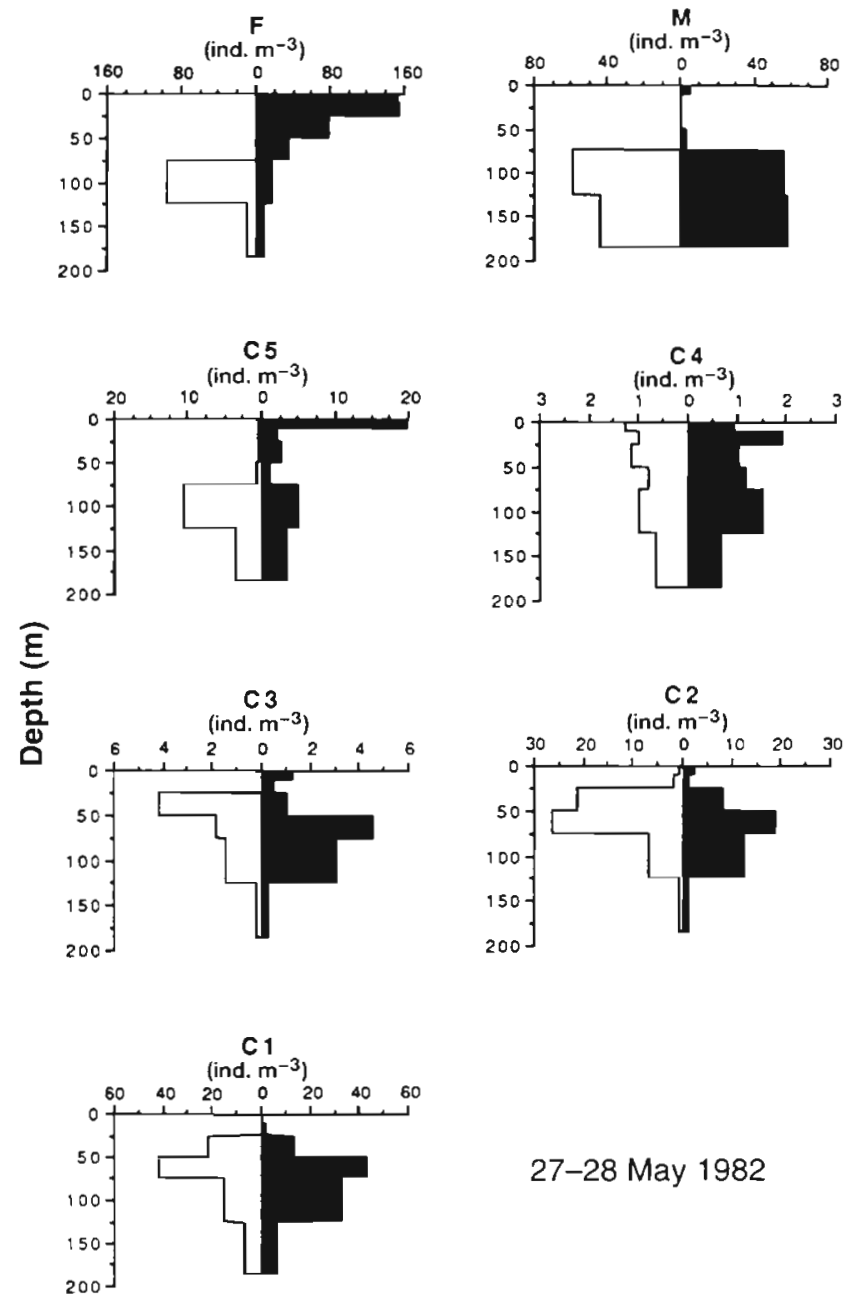

27-28 May 1982

Fig. 10. Metridia lucens. Vertical distributions. As in Fig. 8 except for May 1982 

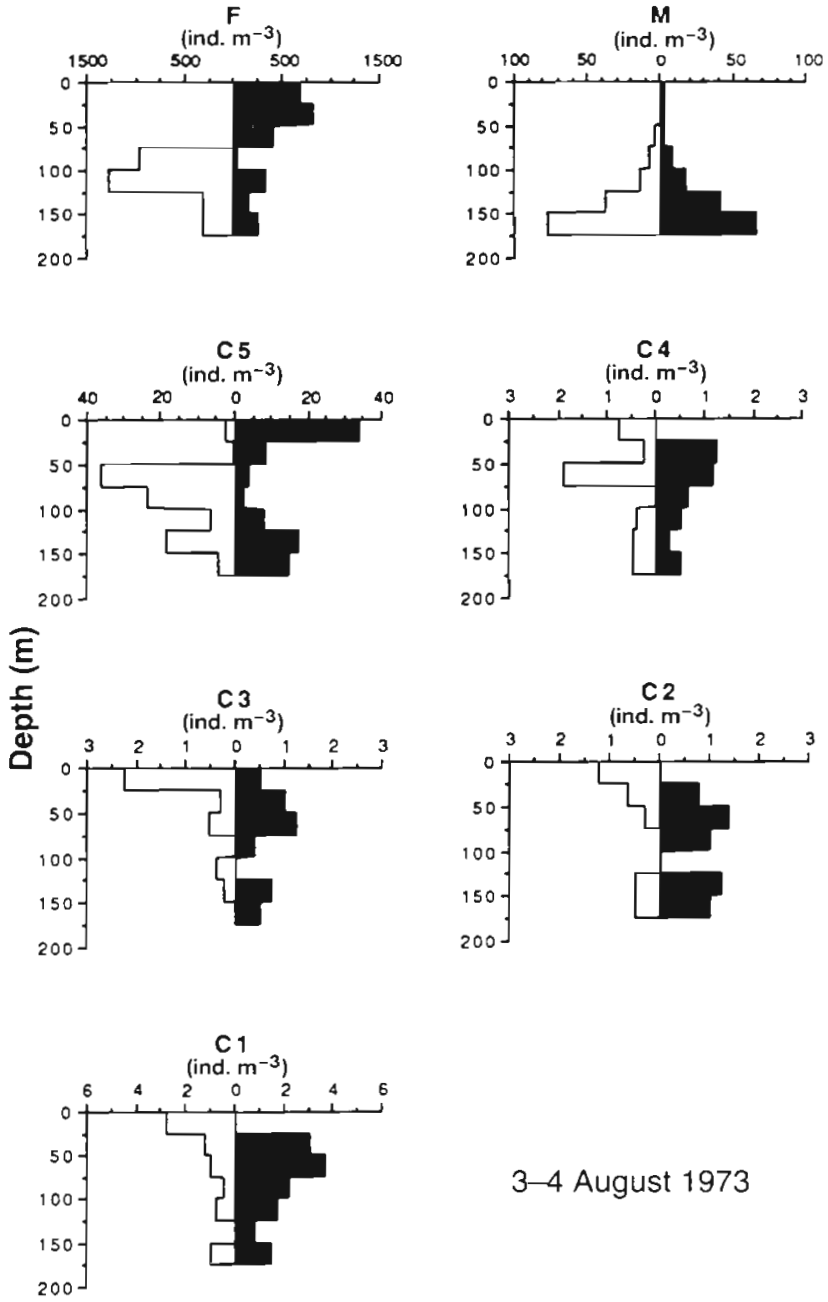

Fig. 11. Metridia lucens. Vertical distributions. As in Fig. 8 except for August 1973

population was there (Figs. 8 \& 11). This led to statistically significant reverse DVM behavior for the C2s in April (Fig. 2). In May 1982, they avoided the surface $25 \mathrm{~m}$ day and night (Fig. 10). Significant reverse DVM behavior was noted for this date too, but here it was due to a movement of the $\mathrm{C} 2 \mathrm{~s}$ in the mid-depths. In September 1982 there were some very fine-scale vertical movements of the C2s. They avoided the surface $10 \mathrm{~m}$ almost entirely during the day, but then at night moved into this layer while the C2s that were in the 25-10 m layer had migrated elsewhere (Fig. 12).

While Metridia lucens C1s were probably not quantitatively sampled with the net mesh size used, the general patterns of vertical distributions are reasonably well represented. The C1s very closely matched the behavior of the C2s. The only exception was during the night in September when the C1s did not avoid the 25-10 m layer (Fig. 12).

\section{Temperature and chlorophyll distributions}

Vertical profiles of the temperature and chlorophyll a concentration show that the water column was stratified during the spring and summer sampling periods (Fig. 13). The temperature decreased rapidly through the top $10 \mathrm{~m}$, but below this the temperature was fairly uniform. The chlorophyll maximum also occurred at or above $10 \mathrm{~m}$ during each cruise; however, the concentrations varied considerably.

\section{DISCUSSION}

The DVM patterns found for Calanus pacificus and Metridia lucens are similar to those observed before, but because of more extensive temporal coverage, particularly for the younger copepodid stages of these 2 species, some unique behaviors were discovered.
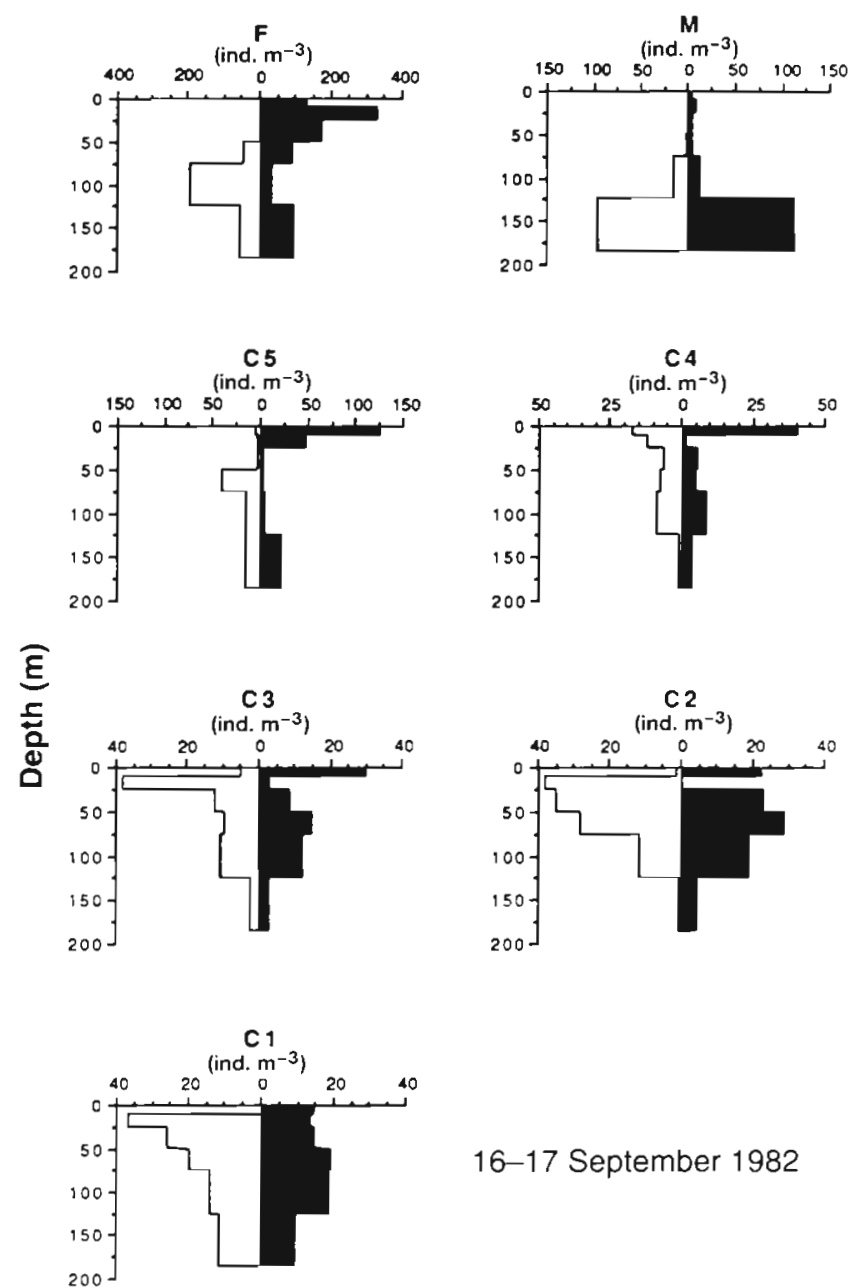

16-17 September 1982
Fig. 12. Metridia lucens. Vertical distributions. As in Fig. 8 except for September 1982 
Fig. 13. Vertical profiles of temperature and chlorophyll a concentration for the dates that copepod vertical distributions are shown in Figs. 3 to 12

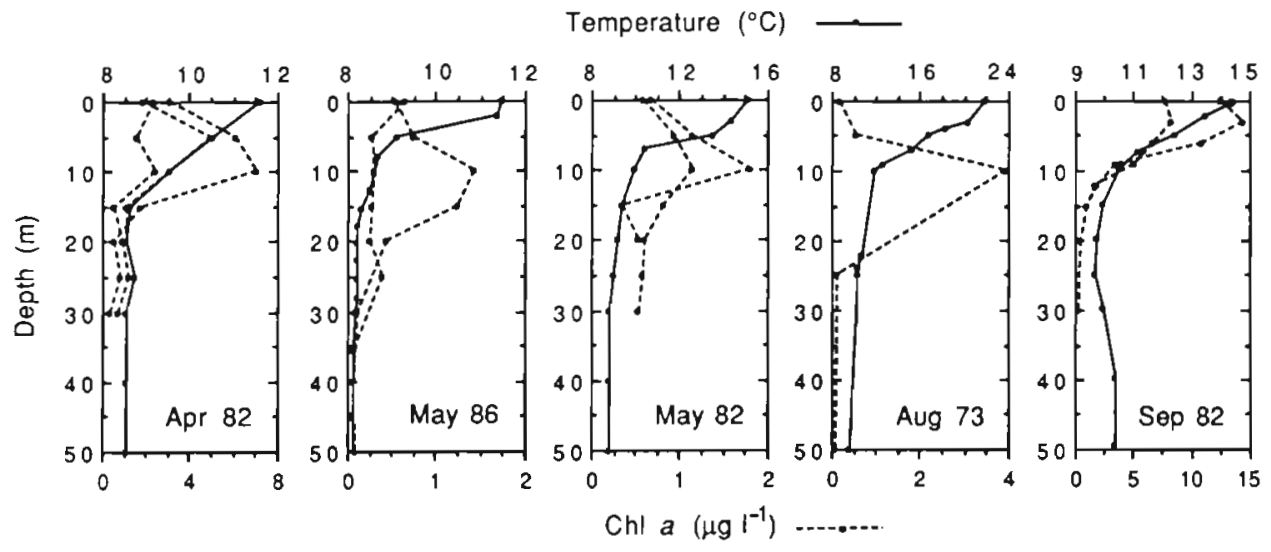

Calanus spp. generally tend to stay near the surface as young developmental stages, but by the time they reach the $\mathrm{C} 4$ or $\mathrm{C} 5$ stage they may show a normal DVM extending down to $50 \mathrm{~m}$ or so (cf. Marshall \& Orr 1955). Such patterns were seen in a population of C. pacificus in the Southern California Bight (Mullin 1986) and in Calanus sinicus, a species closely allied to C. pacificus, in the Inland Sea of Japan (Uye et al. 1990, Huang et al. 1992). However, Williams \& Conway (1984) observed a large portion of all the Calanus helgolandicus copepodid stages in the Celtic Sea migrating over $60 \mathrm{~m}$ in May but only the older copepodids migrating during the summer. The narrow depth range vertical migrations by the younger copepodid C. pacificus reported here had not been documented before in the field, nor had their temporally variable migration behaviors been seen. These types of behaviors were, however, observed in a large tank (Huntley $\&$ Brooks 1982). The one common feature of all known vertical distribution data for C. pacificus is the large percentage of every stage occurring in the surface $50 \mathrm{~m}$ at night (except for C5s when they are in diapause). This is likely due to a requirement to be in the surface layers to feed, as this is where the phytoplankton are and $C$. pacificus are primarily herbivorous (Arashkevich 1969).

Metridia spp, are generally strong diel migrators (Vinogradov 1970) and can be throughout the copepodid stages. Vinogradov (1970) found M. pacifica (= lucens) in the northwestern Pacific to undergo pronounced normal DVM behavior in all the copepodid stages (adult males excluded). Marlowe \& Miller (1975) found that copepodid stages stayed in the surface waters, adult males stayed at depth, and the adult females undertook a pronounced normal DVM at Ocean Stn P $\left(50^{\circ} \mathrm{N}, 145^{\circ} \mathrm{W}\right)$. Batchelder (1985), also working at Stn $\mathrm{P}$, found that the males mostly stayed below $250 \mathrm{~m}$ and the $\mathrm{C} 1 \mathrm{~s}$ and C2s mostly stayed above $100 \mathrm{~m}$ throughout the year. During July and August he found all the other copepodids undergoing normal
DVMs, but in January a smaller percentage of these stages migrated to the surface waters at night, though DVM behavior was still evident. Hattori (1989), working off the northeastern coast of Japan, found that C3s and $\mathrm{C} 4 \mathrm{~s}$ typically had bimodal distributions with peak abundances between 0 to $60 \mathrm{~m}$ and 200 to $300 \mathrm{~m}$. The male C5s were generally distributed like the C3s and $\mathrm{C} 4 \mathrm{~s}$, except at one station where there also was a peak of abundance in the 500 to $600 \mathrm{~m}$ layer. The majority of the female C 5 s stayed between 200 and $300 \mathrm{~m}$ during the day but were bimodally distributed at night as some of the population migrated to the surface waters. The adult males stayed between 200 and $300 \mathrm{~m}$ night and day, while the adult females were distributed much like the C5 females. The reverse DVM, shown by some copepodid stages in this study, is novel for M. lucens. The observed ontogenetic switch from reverse DVM to normal DVM is similar to the switch Neill (1992) found for a freshwater copepod. He related this to different predation pressures on the younger and older stages.

Our results show that not only do the vertical distributions and migration behaviors within a species change between developmental stages, but they also vary between dates and between similar-sized stages of the 2 species. This indicates that factors other than the sizes of the organisms affect their vertical distributions.

\section{Life history effects}

One potentially important factor is seasonality of life history pattern. Most Calanus spp. in temperate regions arrest their development in C5 sometime during the fall and remain in that state through the winter (e.g. Hirche 1983, Alldredge et al. 1984, Miller et al. 1991). C. pacificus in Dabob Bay follows this pattern, as the majority of the population occurs as C5s which stay below $75 \mathrm{~m}$ day and night from about September 
through early March (Frost unpubl. data, this study). This explains the distribution of the C5s in October 1981 and February 1982, when the C5 stage accounts for over $90 \%$ of the copepodid stages of C. pacificus. On the other hand, Metridia spp. do not seem to enter a diapause phase (e.g. Gronvik \& Hopkins 1984, Bamstedt et al. 1985, Batchelder 1985) and overwinter as older copepodid stages and adults. However, there is an indication that in some areas they become less active during the fall and winter, and a smaller percentage of the females migrate at these times (Bamstedt et al. 1985. Hirakawa 1991). This appears to happen in Dabob Bay, where the adult female is the dominant overwintering stage of $M$. lucens (Osgood \& Frost in press). In the February and October samples of this study and the October samples of Bollens et al. (in press), more of the adult female $M$. lucens were staying at depth than at other times of the year. This is surely related to their life history at this locale.

\section{Potential predation effects}

During the spring and summer, predation may account for the differences in the DVM behaviors of Calanus pacificus and Metridia lucens and their developmental stages. The potential role of predation as a selective force driving DVMs has been extensively investigated in Dabob Bay (Ohman et al. 1983, Frost 1988, Bollens \& Frost 1989, Ohman 1990, Bollens et al. 1992, in press, Frost \& Bollens 1992). The abundant planktonic invertebrate predators in Dabob Bay are Euchaeta elongata, Sagitta elegans, and possibly Euphausia pacifica; gelatinous predators occur in low abundance (Ohman 1986, 1990). These abundant invertebrate predators all undergo a normal DVM in Dabob Bay (Ohman et al. 1983). Therefore, to avoid these predators, the copepods would have to undergo a reverse DVM. However, to avoid visually foraging zooplanktivorous fish, they need to display a normal DVM.

Three of the dates for which vertical distributions are reported here represent distinctly different potential. predation regimes. May 1986 was a time when late larval and juvenile Pacific sandlance Ammodytes hexapterus were unusually abundant in Dabob Bay (Bollens \& Frost 1989) and therefore represents a time when potential vertebrate predation on zooplankton was very high. Indeed this was the only date when a normal DVM was observed in Pseudocalanus newmani at this station in Dabob Bay during 5 yr of sampling (Ohman 1990, Frost \& Bollens 1992), perhaps in response to visual predators (Frost \& Bollens 1992). August 1973 was a time of high potential invertebrate predation when $P$. newmani underwent a strong reverse DVM, inferred to be a response to the invertebrate predators (Ohman et al. 1983, Frost \& Bollens 1992). A third date of importance was May 1982. Because the strength of DVM of adult female Calanus pacificus in Dabob Bay is probably influenced by the abundance of zooplanktivorous fish in the upper $50 \mathrm{~m}$ of the water column at night (Bollens \& Frost 1989), May 1982 was possibly a time of relatively low zoaplanktivorous fish abundance since the $C$. pacificus adult females were not migrating (Fig. 5). We next review the data with reference to the predation potentials for these 3 dates to evaluate whether the observed differences in migration behaviors of subadult copepod stages are related to potentially different preda. tion pressures on them.

\section{Responses of Calanus pacificus to predators}

Calanus pacificus stages never avoided the surface layers at night (Figs. 3 to 7). They did, however, show varying degrees of avoidance of the surface layers during the day, suggesting that visual predators can have an impact on the behavior of $C$. pacificus. This implies that either invertebrate predation upon them is not significant, they do not have the plasticity in their behavior to avoid the surface layers at night, or fish predation upon the $C$. pacificus is always more significant than invertebrate predation, and since they need to be in the surface layer to feed at some time, they do so at night.

Of particular interest are the differences in Calanus pacificus migration behaviors between May 1986 and May 1982 (Figs. 4 \& 5). During May 1986, the time of high fish abundance, very few individuals of any copepodid stage were in the top $10 \mathrm{~m}$ during the day and the older the stage - therefore the bigger and more visible the individual - the more deeply distributed they were during the day. In contrast, during May 1982, the date of inferred low fish abundance based on adult female behavior, there were some individuals of all subadult stages even in the top $10 \mathrm{~m}$. Once again the older individuals were distributed more deeply, but strict avoidance of the surface layers was not observed. This demonstrates that $C$. pacificus can perform varied DVMs at least down to the C2 stage and is circumstantial evidence that the subadult stages may be doing it in response to variations in abundance of zooplanktivorous fish.

Alternative explanations for the fine-scale differences in the daytime vertical distributions of the younger copepodid Calanus pacificus include responses to the transparency of the surface waters, food, temperature, salinity, or oxygen gradients, and others. The most tenable of these is an effect of transparency 
of the surface waters, as the effects of the other variables mentioned remain the same through a diel cycle and therefore provide no direct explanation for a migration. If the water was clearer in May 1986 than in May 1982, then the copepods would have had to migrate deeper during the day to reach the same darkness level, and therefore protection level from visual predators. However, from the data on chlorophyll $a$ concentrations there is little indication that this was so (Fig. 13). Huntley \& Brooks (1982) suggested variations in food availability caused varying migrations by C. pacificus in a large tank. When food was scarce the copepods stayed at the surface, while if food was plentiful, they underwent a normal DVM. This was not true for the C. pacificus in Dabob Bay. Chlorophyll concentrations were low in both May 1986 and May 1982; however, the $C$. pacificus behaved very differently, migrating in 1986 but not 1982. In addition, September 1982 was a time of high chlorophyll concentrations, yet there was little indication of DVM by the younger copepodids.

\section{Responses of Metridia lucens to predators}

There was a distinct shift in the behaviors between the C4 and C5 Metridia lucens in August 1973, perhaps in response to different predation pressures on them. While the $\mathrm{C} 4$ and younger stages were avoiding the surface $25 \mathrm{~m}$ at night, presumably to avoid invertebrate predators, the C5s and adults were avoiding the surface $50 \mathrm{~m}$ during the day, presumably to avoid visual predators. This shift in behavior at the $\mathrm{C} 4$ stage is perhaps due to the older stages becoming less vulnerable to invertebrate predation but more vulnerable to visual predators. In Dabob Bay the 2 predation pressures probably switch in their prominence of importance to the $M$. lucens population somewhere around the C4 stage.

Some different behaviors by the $\mathrm{C} 4$ and younger stages of Metridia lucens were found in May 1986 and May 1982 (Figs. 9 \& 10). During May 1986, they strictly avolded the surface $10 \mathrm{~m}$ during the day and also the night, though less strictly; peak abundances of the C3s and $\mathrm{C} 4 \mathrm{~s}$ were between 25 and $10 \mathrm{~m}$ during the day. In May 1982, however, the C4s were not avoiding the surface waters day or night, while the $\mathrm{C} 3$ and younger stages were avoiding the surface $25 \mathrm{~m}$ day and night. A possible explanation for these distributions is that during May 1986, when the zooplanktivorous fish were very abundant, the $\mathrm{C} 4 \mathrm{~s}$ and $\mathrm{C} 3 \mathrm{~s}$ avoided the top $10 \mathrm{~m}$ during the day to avoid visual predators, while at night they tended to avoid the top $10 \mathrm{~m}$ to avoid invertebrate predators that migrated up at night. On the other hand, during May 1982, when fish abundances were inferred to be low (see above), the $\mathrm{C} 3$ and younger stages avoided the surface $25 \mathrm{~m}$ day and night possibly to avoid Sagitta elegans during the day, and to avoid S. elegans in addition to the other invertebrate predators during the night. $S$. elegans do not always migrate out of the surface layers of Dabob Bay in the daytime during the spring (Ohman 1986) and they were observed in the daytime 25-0 m samples of May 1982. The C4s meanwhile did not avoid the surface layers day or night possibly because they were in an intermediate size where their susceptibility to fish predation was reduced compared to C5s and their susceptibility to invertebrate predation was reduced compared to $\mathrm{C} 3 \mathrm{~s}$. In contrast to Calanus pacificus, the migration behaviors of the C5 and adult female $M$. lucens did not vary greatly between these 2 dates. The adult females of M. lucens always had their peak abundances at depth during the daytime. This aspect of their migration behavior seems inflexible (see Bollens et al. in press)

\section{Other behaviors of interest}

The September 1982 vertical distributions of Metridia lucens are intriguing. All the stages except the $\mathrm{C} 4 \mathrm{~s}$ avoided at least the surface $10 \mathrm{~m}$ during the day, presumably to avoid visual predators. One of the 2 daytime abundance profiles for the $\mathrm{C} 4 \mathrm{~s}$ (not shown) showed this stage avoiding the surface $10 \mathrm{~m}$, but the other profile, taken at approximately 18:00 $\mathrm{h}$, looked like the nighttime profiles. It could be that these $\mathrm{C} 4 \mathrm{~s}$ had migrated to their nighttime positions by $18: 00 \mathrm{~h}$. This contrasts with all the other $M$. lucens stages in September for which the 2 daytime profiles look very similar.

A final curious aspect about some of the vertical abundance profiles is the tendency for bimodal vertical distributions due to an apparent avoidance of the 75-50 m layer, especially in some of the older copepodid stages of both species. For stages exhibiting this behavior at night, it was likely because only a portion of the population migrated to the surface layers at night. Dagg et al. (1989) found a peak in the gut pigment concentrations of adult female Calanus pacificus and Metridia lucens below $50 \mathrm{~m}$ during the early morning as the females that had been feeding in the surface layers throughout the night descended to depth. For stages exhibiting bimodal distributions during the day and night, it may have been due to asynchronous migrations of individuals throughout the day or more static bimodal distributions (Pearre 1979). In all cases the copepods occurred infrequently in intermediate depths and it is of interest why. Possibilities include an increased abundance of predators in the layer, or reduced food availability in this layer com- 
pared to the surface $50 \mathrm{~m}$, yet still enough light here during the day such that visual predators could feed. Therefore, the copepods either go above this layer to feed or stay below it, where they are safe from visual predation day and night.

\section{CONCLUSIONS}

Why similar-sized stages of Calanus pacificus and Metridia lucens should have such different migration behaviors is puzzling if it is presumed that body size is the major factor controlling susceptibility to predation and that predation is what causes vertical migrations Bollens et al. (in press) examined this question for adult females of the 2 species. Although size is important for prey selection by visual and non-visual predators (e.g. Brooks 1968, Landry 1978, Sullivan 1980, Koslow 1981, Yen 1985) swimming motion is also important (Reeve 1966, Newbury 1972, Kislalioglu \& Gibson 1976, Gerritsen \& Strickler 1977, Drenner et al. 1978, Zaret 1980 Jansen 1982, Yen 1985, Kimmerer \& McKinnon 1989 Ramcharan \& Sprules 1991). M. lucens is a more continuously active swimmer than C. pacificus (Mackas \& Burns 1986, Dagg et al. 1989) and this difference in swimming behaviors could differentially affect the predation rates on the 2 species. $M$. lucens copepodids may be more susceptible to invertebrate predators and this may be why they show a reverse DVM at times whereas the copepodids of C. pacificus do not. Stuart \& Huggett (1992) found Euphausia lucens to ingest adult M. lucens at higher rates than other similar-sized prey, including stages of Calanus agulhensis. A similar euphausiid, Euphausia pacifica, is a potential predator in Dabob Bay (Ohman 1984). Yen (1985), however, found lower predation rates by Euchaeta elongata on adult $M$. lucens than on similar-sized $C$. pacificus. Alternatively, it may be that, in terms of effects on population growth, $M$. lucens is more sensitive to predation than $C$. pacificus, due to its lower fecundity (see Bollens et al. in press). Finally, it may just be that $M$. lucens has the ability to exhibit a wide variety of migration behaviors during its developmental stages, but $C$. pacificus is constrained to either normal DVM or staying near the surface night and day. The young copepodid stages of $C$. pacificus do appear much more closely tied to the surface layers than those of $M$. lucens, and this may affect the diversity of migration behaviors they are able to exhibit, and is perhaps an indication of differing diets. Quantification of different predator preferences for different stages and species, along with the distributions and abundances of the predators, would allow more definite conclusions on why DVM behavior varies between species and between the different stages of a single species.
Acknowledgements. This work was supported by U.S. National Science Foundation grant OCE 89-17671 to B.W.F. Special thanks to G. A. Heron and to all those who helped collect the field samples. We also thank 3 anonymous reviewers for their constructive comments on the manuscript. Contribution No. 1981, School of Oceanography, University of Washington

\section{LITERATURE CITED}

Alldredge, A. L., Robison, B. H., Fleminger, A., Torres, J. J., King, J. M., Hammner, W. M. (1984). Direct sampling and in situ observation of a persistent copepod aggregation in the mesopelagic zone of the Santa Barbara Basin. Mar. Biol. 80: 75-81

Arashkevich, Y. G. (1969). The food and feeding of copepods in the northwestern Pacific. Oceanology 9:695-709

Bamstedt, U., Tande, K. S., Nicolajsen, H. (1985). Ecological investigations on the zooplankton community of Balsfjorden, northern Norway: physiological adaptations in Metridia longa (Copepoda) to the overwintering period. In: Gray, J. S., Christiansen, M. E. (eds.) Marine biology of polar regions and effects of stress on marine organisms. John Wiley \& Sons, Chichester, p. 313-327

Batchelder, H. P. (1985). Seasonal abundance, vertical distribution, and life history of Metridia pacifica (Copepoda: Calanoida) in the oceanic subarctic Pacific. Deep Sea Res. 32: 949-964

Boliens, S. M., Frost, B. W. (1989). Zooplanktivorous fish and variable diel vertical migration in the marine planktonic copepod Calanus pacificus. Limnol. Oceanogr. 34: $1072-1083$

Bollens, S. M., Frost, B. W., Lin, T. S. (1992). Recruitment, growth, and diel vertical migration of Euphausia pacifica in a temperate fjord. Mar. Biol. 114: 219-228

Bollens, S. M., Osgood, K. E., Frost, B. W., Watts, S. D. (in press). Comparative vertical distributions and susceptibilities to vertebrate predation of the marine copepods Metridia lucens and Calanus pacificus. Limnol. Oceanogr.

Brooks, J. L. (1968). The effects of prey size selection by lake planktivores. Syst. Zool. 17: 273-291

Dagg, M. J., Frost, B. W., Walser, W. E. Jr (1989). Copepod diel migration, feeding, and their vertical flux of pheopigments. Limnol. Oceanogr. 34: 1062-1071

Drenner, R. W., Strickler, J. R., O'Brien, W. J. (1978). Capture probability: the role of zooplankter escape in the selective feeding of planktivorous fish. J. Fish. Res. Bd Can. 35: $1370-1373$

Frost, B. W. (1988). Variability and possible adaptive significance of diel vertical migration in Calanus pacificus, a planktonic marine copepod. BuIl. mar. Sci. 43: 675-694

Frost, B. W., Bollens, S. M. (1992). Variability of diel vertical migration in the manne planktonic copepod Pseudocalanus newmani in relation to its predators. Can. J. Fish. Aquat. Sci. 49: 1137-1141

Gardner, G. A., Szabo, I. (1982). British Columbia pelagic marine copepoda: an identification manual and annotated bibliography. Can. Spec. Publ. Fish. Aquat. Sci. 62

Gerritsen, J., Strickler, J. R. (1977). Encounter probabilities and community structure in zooplankton: a mathematical model. J. Fish. Res. Bd Can. 34: 73-82

Gronvik, S. Hopkins, C. C. E. (1984). Ecological investigations of the zooplankton community of Balsfjorden, northern Norway: generation cycle, seasonal vertical distribution, and seasonal variations in body weight and carbon and nitrogen content of the copepod Metridia longa (Lubbock). J. exp. mar. Biol. Ecol. 80: 93-107 
Hattori, H. (1989). Bimodal vertical distribution and diel migration of the copepods Metridia pacifica, $M$ okhotensis and Pleuromamma scutullata in the western North Pacific Ocean. Mar. Biol. 103: 39-50

Hirakawa, K. (1991). Vertical distribution and reproduction of planktonic copepods in Toyoma Bay, southern Japan Sea, with special reference to Metridia pacifica. Proceedings of the 4 th International Conference on Copepods. Bull. Plankton Soc. Japan, Spec. Vol. (1991): 373-382

Hirche, H.-J. (1983). Overwintering of Calanus finmarchicus and Calanus helgolandicus. Mar. Ecol. Prog. Ser. 11: $281-290$

Huang, C., Uye, S., Onbe, T. (1992). Ontogenetic diel vertical migration of the planktonic copepod Calanus sinicus in the Inland Sea of Japan. II. Late fall and early spring. Mar. Biol. 113: 391-400

Huntley, M., Brooks, E. R. (1982). Effects of age and food availability on diel vertical migration of Calanus pacificus. Mar. Biol. 71: 23-31

Jansen, J. (1982). Comparison of searching behavior for zooplankton in an obligate planktivore, blueback herring (Alosa aestivelis) and a facultative planktivore, bluegill (Lepomis machrochirus). Can. J. Fish. Aquat. Sci. 39: $1649-1654$

Kimmerer, W. J., McKinnon, A. D. (1989). Zooplankton in a marine bay. III. Evidence for influence of vertebrate predation on distributions of two common copepods. Mar. Ecol. Prog. Ser. 53: 21-35

Kislalioglu, K., Gibson, R. N. (1976). Some factors governing prey selection by the 15-spined stickleback, Spinachia spinachia (L.). J. exp. mar. Biol. Ecol. 25: 159-169

Koslow, J. A. (1981). Feeding selectivity in schools of northern anchovy (Engraulis mordax) in the southern California Bight. Fish. Bull. U.S. 79: 131-142

Lampert, W. (1989). The adaptive significance of diel vertical migration of zooplankton. Functional Ecol. 3: 21-27

Landry, M. R. (1978). Predatory feeding behavior of a marine copepod, Labidocera trispinosa. Limnol. Oceanogr. 23: $1103-1113$

Mackas, D. L., Burns, K. E. (1986). Post starvation feeding and swimming activity in Calanus pacificus and Metridia pacifica. Limnol. Oceanogr. 31: 383-392

Marlowe, C. J., Miller, C. B. (1975). Patterns of vertical distribution and migration of zooplankton at Ocean Station ' $\mathrm{P}$ '. Limnol. Oceanogr. 20: 824-844

Marshall, S. M., Orr, A. P. (1955). The biology of a marine copepod. Oliver and Boyd, Edinburgh

Miller, C. B., Cowles, T. J., Wiebe, P. H., Copley, N. J., Grigg, H. (1991). Phenology in Calanus finmarchicus; hypotheses about control mechanisms. Mar. Ecol. Prog. Ser. 72: $79-91$

Miller, C. B., Frost, B. W., Batchelder, H. P., Clemons, M. J., Conway, R. E. (1984). Life histories of large, grazing copepods in a subarctic ocean gyre: Neocalanus plumchrus, Neocalanus cristatus, and Eucalanus bungii in the northeast Pacific. Prog. Oceanogr. 13: 201-243

Minoda, T. (1971). Pelagic copepoda in the Bering Sea and the northwestern north Pacific with special reference to their vertical distribution. Mem. Fac. Fish. Hokkaido Univ. 18: $1-74$

This article was submitted to the editor
Mullin, M. M. (1986). Spatial and temporal scales and patterns. In: Eppley, R. W. (ed.) Plankton dynamics of the Southern California Bight. Springer-Verlag. New York, p. $216-273$

Neill, W. E. (1992). Population variation in the ontogeny of predator-induced vertical migration of copepods. Nature 356: $54-57$

Newbury, T. K. (1972). Vibration perception by chaetognaths. Nature 236: $459-460$

Ohman, M. D. (1984). Omnivory by Euphausia pacifica: the role of copepod prey. Mar. Ecol. Prog. Ser. 19: 125-131

Ohman, M. D. (1986). Predator-limited population growth of the copepod Pseudocalanus sp. J. Plankton Res. 8: $673-713$

Ohman, M. D. (1990). The demographic benefits of diel vertical migration by zooplankton. Ecol. Monogr. 60: 257-281

Ohman, M. D., Frost, B. W., Cohen, E. B. (1983). Reverse diel vertical migration: an escape from invertebrate predators. Science 220: 1404-1407

Osgood, K. E., Frost, B. W. (in press). Comparative life histories of three species of planktonic calanoid copepods in Dabob Bay, Washington. Mar. Biol.

Park, T. S. (1968). Calanoid copepods from the central north Pacific Ocean. Fish. Bull. U.S. 66: 527-572

Pearre, S., Jr. (1979). Problems of detection and interpretation of vertical migration. J. Plankton Res. 1: 29-44

Ramcharan, C. W., Sprules, W. G. (1991). Predator-induced behavioral defense and its ecological consequences for two calanoid copepods. Oecologia 86: 276-286

Reeve, M. R. (1966). Observations on the biology of a chaetognath. In: Barnes, H. (ed.) Some contemporary studies in marine science. Allen and Unwin, London, p. 613-630

Star, J. L., Mullin, M. M. (1981). Zooplanktonic assemblages in three areas of the North Pacific as revealed by continuous horizontal transects. Deep Sea Res. 28A: 1303-1322

Stuart, V., Huggett, J. A. (1992). Prey selection by Euphausia lucens (Hansen) and feeding behavior in response to a mixed algal and animal diet. J. exp. mar. Biol. Ecol. 164: $117-133$

Sullivan, B. K. (1980). In situ feeding behavior of Sagitta elegans and Eukhronia hamata (Chaetognatha) in relation to the vertical distribution and abundance of prey at Ocean Station "P". Limnol. Oceanogr. 25: 317-326

Uye, S., Huang, C., Onbe, T. (1990). Ontogenetic diel vertical migration of the planktonic copepod Calanus sinicus in the Inland Sea of Japan. Mar. Biol. 104: 389-396

Vinogradov, M. E. (1970). Vertical distribution of the oceanic zooplankton. Akademiya Nauk SSSR Institute Okeanologii, translated by Israel Program for Scientific Translations, Jerusalem

Williams, R. Conway, D. V. P. (1984). Vertical distribution, and seasonal and diurnal migration of Calanus helgolandicus in the Celtic Sea. Mar. Biol. 79: 63-73

Yen, J. (1985). Selective predation by the carnivorous marine copepod Euchaeta elongata: laboratory measurements of predation rates verified by field observations of temporal and spatial feeding patterns. Limnol. Oceanogr. 30: $577-597$

Zaret, T. M. (1980). Predation and freshwater communities. Yale, New Haven

Manuscript first received: May 12, 1993

Revised version accepted: October 28, 1993 